\title{
Pleural Fluid Supernatant
}

National Cancer Institute

\section{Source}

National Cancer Institute. Pleural Fluid Supernatant. NCI Thesaurus. Code C106559.

The liquid lying above a liquid, solid or semi-solid residue, which is separated by

crystallization, precipitation or centrifugation of a pleural fluid sample. 